\title{
Microbial carbon recycling - an underestimated process controlling soil carbon dynamics - Part 1: A long-term laboratory incubation experiment
}

\author{
A. Basler ${ }^{1}$, M. Dippold ${ }^{2}$, M. Helfrich ${ }^{3}$, and J. Dyckmans ${ }^{1}$ \\ ${ }^{1}$ Centre for Stable Isotope Research and Analysis, Büsgen Institute, Georg-August-University Göttingen, \\ Göttingen, Germany \\ ${ }^{2}$ Department of Agricultural Soil Science, Georg-August-University Göttingen, Göttingen, Germany \\ ${ }^{3}$ Thünen-Institute of Climate-Smart Agriculture, Braunschweig, Germany
}

Correspondence to: A. Basler (abasler@gwdg.de)

Received: 10 April 2015 - Published in Biogeosciences Discuss.: 15 June 2015

Accepted: 29 September 2015 - Published: 19 October 2015

\begin{abstract}
Independent of its chemical structure carbon (C) persists in soil for several decades, controlled by stabilization and recycling. To disentangle the importance of the two factors on the turnover dynamics of soil sugars, an important compound of soil organic matter (SOM), a 3-year incubation experiment was conducted on a silty loam soil under different types of land use (arable land, grassland and forest) by adding ${ }^{13} \mathrm{C}$-labelled glucose. The compound-specific isotope analysis of soil sugars was used to examine the dynamics of different sugars during incubation.
\end{abstract}

Sugar dynamics were dominated by a pool of high mean residence times (MRT) indicating that recycling plays an important role for sugars. However, this was not substantially affected by soil $\mathrm{C}$ content. Six months after label addition the contribution of the label was much higher for microbial biomass than for $\mathrm{CO}_{2}$ production for all examined land use types, corroborating that substrate recycling was very effective within the microbial biomass. Two different patterns of tracer dynamics could be identified for different sugars: while fucose and mannose showed highest label contribution at the beginning of the incubation with a subsequent slow decline, galactose and rhamnose were characterized by slow label incorporation with subsequently constant levels, which indicates that recycling is dominating the dynamics of these sugars. This may correspond to (a) different microbial growing strategies ( $r$ and $K$-strategist) or (b) location within or outside the cell membrane (lipopolysaccharides vs. exopolysaccharides) and thus be subject of different re-use within the microbial food web. Our results show how the microbial community recycles substrate very effectively and that high losses of substrate only occur during initial stages after substrate addition. This study indicates that recycling is one of the major processes explaining the high MRT observed for many SOM fractions and thus is crucial for understanding the global soil $\mathrm{C}$ cycle.

\section{Introduction}

Organic matter that enters the soil is immediately subject to microbial degradation (Fontaine et al., 2003). It has long been assumed that the chemical structure of soil organic matter (SOM) compounds is a key factor controlling decomposition dynamics (Stevenson, 1994). However, in recent years, several studies have shown that carbon (C) compounds are persistent in soil independent of their chemical structure and that mean residence times (MRT) of many compound classes are in the same range (Derrien et al., 2006; Amelung et al., 2008; Gleixner et al., 2002; Kiem and Kögel-Knabner, 2003; Derrien et al., 2007; Schmidt et al., 2011). Two main mechanisms have been discussed to control the $\mathrm{C}$ dynamics in soil: on the one hand preservation of SOM due to stabilization and on the other hand recycling, i.e. the synthesis of $\mathrm{C}$ compounds from old C sources (Gleixner et al., 2002; Sauheitl et al., 2005; Six et al., 2002; von Lützow et al., 2006; Sollins et al., 1996). 
The question of stabilization vs. recycling is particularly imminent for sugars: their high degradability and usability suggest a rapid turnover in soils. In contrast, sugars are characterized by high turnover times, similar to bulk soil C (Gleixner et al., 2002; Derrien et al., 2007). While chemical recalcitrance can be ruled out, it is unknown whether spatial inaccessibility and interactions with surfaces and metal ions on the one hand or recycling on the other hand are predominant for the observed high apparent MRT (where "apparent MRT" refers to the MRT of the compound as opposed to the MRT of the underlying C). Vascular plant-derived carbohydrates are mainly characterized by the pentose sugars arabinose (ara) and xylose (xyl), whereas hexoses (galactose (gal), and manose (man)) and desoxyhexoses (fucose (fuc) and rhamnose (rha)) are primarily produced by microorganisms (Moers et al., 1990).

Studies that aim to disentangle contribution of recycling and stabilization to the fate of carbohydrates are rare. Based on exponential decay functions, several studies suggest the existence of different sugar pools in soils (Cheshire et al., 1988; Derrien et al., 2007; Muramaya, 1984). Derrien et al. (2007) and Muramaya (1988) performed glucose incubation experiments with incubation periods up to 1 year, but conclusion about factors controlling the long-term decay kinetics of soil sugars were not possible, presumably due to the short duration of the experiment and a low number of sampling times. The aim of the present study was to investigate the long-term decay of different (plant and microbial derived) sugars in soil. Therefore, a 3-year incubation experiment combined with short sampling intervals was set up to evaluate whether sugar pools with different turnover dynamics can be identified in soil during long-term incubation. The incubation was performed on a silty loam under different land use types (and hence soil $\mathrm{C}$ concentrations and chemical qualities) to assess the influence of soil $\mathrm{C}$ content on microbial recycling. We hypothesize (i) that the high MRT of soil sugars that have often been observed results mainly from microbial recycling and not from stabilization processes and (ii) that the importance of microbial recycling increases with decreasing soil $\mathrm{C}$ content.

\section{Material/methods}

\subsection{Study site}

Soil samples were collected from the long-term field experiment at "Höhere Landbauschule" Rotthalmünster, Bavaria, Germany $\left(48^{\circ} 21^{\prime} 47^{\prime \prime} \mathrm{N}, 13^{\circ} 11^{\prime} 46^{\prime \prime} \mathrm{E}\right)$. The mean annual temperature is $9.2^{\circ} \mathrm{C}$ and the mean annual precipitation is $757 \mathrm{~mm}$. Soil samples were taken in April 2011 from the following sites and soil depths: (i) the Ap horizon $(0-30 \mathrm{~cm})$ and (ii) the E horizon $(30-45 \mathrm{~cm})$ of a continuous wheat plot (Triticum aestivum L.) established in 1969. Previous vegetation on the wheat plot was grassland. (iii) The Ah hori- zon $(0-10 \mathrm{~cm})$ of a grassland established in 1961 and (iv) the Ah horizon $(0-10 \mathrm{~cm})$ of a nearby spruce stand. The soil was classified as a stagnic Luvisol derived from loess (IUSS Working Group WRB, 2014). The soil texture is silty loam. Field moist soil was carefully sieved to $2 \mathrm{~mm}$ and stored at $10^{\circ} \mathrm{C}$ until use. The soils are described in detail by John et al. (2005) and Helfrich et al. (2006).

\subsection{Soil incubation}

For incubation, $1000 \mathrm{~g}$ dry weight (dw) soil of the wheat Ap and $\mathrm{E}$ horizon and $700 \mathrm{~g} \mathrm{dw}$ soil of the grassland and forest Ah horizon were placed individually in microcosms, with three replicates for each site and depth. The soil was not compacted and equal filling levels of the microcosms resulted for all soils. The soil was amended with $400 \mathrm{mg} 99 \%$ uniformlylabelled $\left[\mathrm{U}^{13} \mathrm{C}\right]$ glucose (Euroisotrop, Saint-Aubin, France) equivalent to a $\mathrm{C}$ addition of 3,5,2 and $1 \%$ of total organic $\mathrm{C}\left(\mathrm{C}_{\text {org }}\right)$ in the wheat Ap, E, grassland and forest soil, respectively. The glucose was applied in solution to the soil while adjusting the water holding capacity of $50 \%$, thoroughly mixed and filled in the microcosms. The microcosms were incubated for 34 months at a constant temperature of $10^{\circ} \mathrm{C}$, representing the mean annual soil temperature in Rotthalmünster. The microcosms were kept semi-closed to enable aeration and to reduce drying-out at the same time. Every 2 weeks approximately $4 \mathrm{~g}$ of soil was removed from each microcosm and additionally $20 \mathrm{~g}$ after 6,20 and 34 months of incubation for soil microbial biomass analysis. On these occasions, the complete soil was taken out of the microcosms, thoroughly mixed and carefully rewetted by sprinkling with deionized water to keep fluctuations of soil water content below $10 \%$. The soil samples were stored at $-18^{\circ} \mathrm{C}$ until extraction. Controls under natural abundance conditions were treated identically.

\section{$2.3 \mathrm{CO}_{2}$ respiration}

The $\mathrm{CO}_{2}$ respiration was measured biweekly before soil sampling. At first, microcosms were closed and a headspace sample was taken after approximately $30 \mathrm{~min}$ of equilibration. With an air tight syringe, $50 \mathrm{~mL}$ of synthetic air was pushed into the vessel and the headspace was mixed by pumping the syringe 3 to 4 times. Afterwards $50 \mathrm{~mL}$ of the headspace air was taken and transferred to pre-evacuated Exetainers (Labco Limited, Buckinghamshire, UK). A second headspace sample was taken identically after $24 \mathrm{~h}$ of $\mathrm{CO}_{2}$ accumulation in the closed microcosms. The $\mathrm{CO}_{2}$ concentrations and isotopic values were measured by an IRMS Delta Plus with GP interface and GC-Box (ThermoFisher, Bremen, Germany) and the amount of the produced $\mathrm{CO}_{2}$ was calculated from the difference in concentration and isotopic composition of the two samplings. 


\section{$2.4 \quad{ }^{13} \mathrm{C}$ analysis of individual sugars}

\subsubsection{Extraction procedure}

Carbohydrates were extracted and purified using a modified procedure based on Amelung et al. (1996) as described by Basler and Dyckmans (2013). The sugars were extracted from $500 \mathrm{mg}$ wet soil by hydrolysis with $10 \mathrm{~mL} 4 \mathrm{M}$ trifluoroacetic acid (TFA) and at $105^{\circ} \mathrm{C}$ for 4 hours. Afterwards, the samples were filtered through a glass fibre filter (Minisart GF, Sartorius, Göttingen, Germany) and dried by rotary evaporation $\left(40^{\circ} \mathrm{C}, 50 \mathrm{hPa}\right)$. The samples were re-dissolved with $0.5 \mathrm{~mL}$ water and evaporated to dryness 3 times to remove all traces of TFA. After the evaporation process the samples were re-dissolved in approximately $3 \mathrm{~mL}$ water and passed through $4 \mathrm{~g}$ Dowex X8 cation exchange resin (Sigma Aldrich, Steinheim, Germany) and $5 \mathrm{~g}$ Serdolit PAD IV adsorption resin (Serva Electrophoresis GmbH, Heidelberg, Germany) for purification. Carbohydrates were eluted from the resin by adding 8 times $2 \mathrm{~mL}$ water. The eluate was freeze-dried and stored at $-18^{\circ} \mathrm{C}$ until analysis. For HPLC/o/IRMS analysis the samples were dissolved in $3 \mathrm{~mL}$ water.

The TFA extraction method is known to effectively extract hemi-cellulosic sugars but cellulose is not cleaved by this method (Amelung et al., 1996). The results presented here thus only refer to non-cellulosic sugars.

\subsubsection{Sugar analysis}

The compound specific analysis of amounts and isotope ratios were performed using a high-pressure liquid chromatography system (Sykam, Fürstenfeldbruck, Germany) coupled to an isotope ratio mass spectrometer (Delta V Advantage, Thermo Scientific, Bremen, Germany) via an LC-Isolink interface (Thermo Scientific, Bremen, Germany) as described by Basler and Dyckmans (2013). Shortly, the chromatographic column (Carbo Pac 20, Dionex, Germering, Germany) was held at $10^{\circ} \mathrm{C}$ and a $0.25 \mathrm{mM} \mathrm{NaOH}$ solution was used as mobile phase at a flow rate of $250 \mu \mathrm{L} \mathrm{min}^{-1}$.

The isotopic values are reported in atm \%excess notation:

$\mathrm{atm} \%$ excess $=\mathrm{atm} \%$ labelled $-\mathrm{atm} \%$ unlabelled.

The analysis frequency differed among the different types of land use: to check if short sampling intervals will reveal additional sugar dynamics, all samples (i.e. 2-week intervals) from the incubation of the wheat Ap horizon were analysed for the 30-month sampling period. However, as the results did not indicate a multi-pool dynamic, (see Results, Fig. 4), the frequency of analysis was reduced for the other sites. From the forest and grassland incubations, samples were analysed in 4-week intervals over a 24-month period, and from the wheat $\mathrm{E}$ horizon, samples were analysed in 8-week intervals for a period of 30 months. Sugar analysis was made from only one microcosm to account for time-dependent dy- namics rather than differences among different incubations. To assess the variability among different microcosms, after 6 and 24 months, all incubation microcosms were analysed for sugar content and isotopic composition. The mean coefficient of variation among the replicates was below $5 \%$, therefore the results of the incubations presented here are taken as representative.

\subsection{Chloroform-fumigation-extraction}

The soil microbial biomass $\left(\mathrm{C}_{\mathrm{mic}}\right)$ was measured before and after 6, 20 and 34 months of incubation by the chloroformfumigation extraction method (Brookes et al., 1985; Vance et al., 1987). In brief, each sample was divided into two sub-samples of $10 \mathrm{~g}$ moist soil. One soil sub-sample was directly extracted as described below. The other sub-sample was placed in a desiccator together with $80 \mathrm{~mL}$ of ethanol free $\mathrm{CH}_{3} \mathrm{Cl}$. Desiccators were evacuated and the samples were left at $25^{\circ} \mathrm{C}$ for $24 \mathrm{~h}$ (fumigation). All samples were extracted by shaking with $60 \mathrm{~mL} 0.05 \mathrm{M} \mathrm{K}_{2} \mathrm{SO}_{4}$ (Engelking et al., 2008) for 1 hour and subsequently filtered (Whatman $5951 / 2$, Maidstone, UK). The soil extracts were analysed for their $\mathrm{C}$ content using a TOC analyser multi $\mathrm{C} / \mathrm{N}^{\circledR} 2000$ (Analytik Jena, Jena, Germany). For stable isotope measurements, around $50 \mathrm{mg}$ of the freeze-dried filtrates were filled in tin capsules and analysed by elemental analyser/isotope ratio mass spectrometry (EA/IRMS) using a EuroVector elemental analyser (HEKAtech GmbH, Wegberg, Germany) coupled to a Delta Plus XP isotope ratio mass spectrometer (Thermo Scientific, Bremen, Germany). Samples are combusted in a reactor filled with tungsten oxide and silvered cobaltous oxide at $1020^{\circ} \mathrm{C}$.

The isotopic signature of the microbial biomass $\mathrm{C}$ was calculated as follows:

$\operatorname{atm} \% \operatorname{excess} C_{\text {mic }}=\frac{\left(\operatorname{atm} \% \operatorname{excess} C_{\mathrm{F}} \cdot C_{\mathrm{F}}\right)-\left(\operatorname{atm} \% \operatorname{excess} C_{\mathrm{nF}} \cdot C_{\mathrm{nF}}\right)}{\left(C_{\mathrm{F}}-C_{\mathrm{nF}}\right)}$,

where atm\%excess $C_{\mathrm{F}}$ and atm\%excess $C_{\mathrm{nF}}$ are the isotopic composition of the fumigated and non-fumigated extracts and $C_{\mathrm{F}}$ and $C_{\mathrm{nF}}$ are the $\mathrm{C}$ concentrations in the extracts of the fumigated and non-fumigated soil samples, respectively. For calculation of total microbial biomass-C, a $k_{\text {ec }}$ factor of 0.45 was used (Joergensen, 1996). Carbon extracted from non-fumigated samples represents the $\mathrm{K}_{2} \mathrm{SO}_{4}$ extractable $\mathrm{C}$ fraction (exC).

\subsection{Calculation and statistics}

All statistical analyses and modelling were performed with R 3.0.2 (R Core Team, 2013).

The relative specific allocation (RSA) describes the fraction of labelled $\mathrm{C}$ relative to total $\mathrm{C}$ in a given compartment (Deleens et al., 1994; Dyckmans and Flessa, 2002) and is calculated as follows:

$\mathrm{RSA}=\frac{\text { atom } \%_{\text {sample }}-\text { atom } \%_{\text {control }}}{\text { atom } \%_{\text {label }}-\text { atom } \%_{\text {control }}}$ 
The partitioning $(P)$ describes the proportion of the labelled element in a given soil $\mathrm{C}$ compartment relative to the total labelled element in the whole (Deleens et al., 1994; Dyckmans and Flessa, 2002). The partitioning of labelled $\mathrm{C}$ was calculated from:

$P[\%]=\frac{\mathrm{RSA}_{\text {fraction }} \cdot A_{\text {fraction }}}{\mathrm{RSA}_{\text {bulksoil }} \cdot A_{\text {bulksoil }}}$

where $A$ is the amount of the respective fraction.

The following exponential functions were used to analyse decay kinetics for each individual sugar:

mono exponential function

$y=a \cdot e^{\left(-k_{1} t\right)}$

bi-exponential function

$y=a \cdot e^{\left(-k_{1} \cdot t\right)}+b \cdot e^{\left(-k_{2} \cdot t\right)}$.

In the equations, $y$ represents the RSA value of individual sugar; $k$ the decay constant of the sugar pool, and $a$ and $b$ represent initial pool sizes.

The MRT of $C$ in the respective sugar pool was calculated according to Derrien and Amelung (2011):

$\operatorname{MRT}=1 / k$,

where $k$ is the decay constant estimated by fitting Eqs. (5) or (6) to the measured values.

Equations (5) and (6) were fitted to the data using R. The best model for each sugar and soil was identified using the Akaike information criterion (AIC; Akaike, 1998). The AIC is defined as

$\mathrm{AIC}=2 z-2 \ln (L)$

where $z$ is the number of parameters in the model and $L$ the maximized value of the likelihood function for the model.

A Pearson correlation test was conducted to determine the relationship between distributions of labelled sugar and total sugar of the organic matter and to test the model efficiency. The statistical significance of the sugar composition, ratios and label-derived proportions among different sugars, sampling times were tested by Kruskal-Wallis one-way analysis of variance.

\section{Results}

\subsection{Carbon concentrations and incorporation of the labelled $\mathrm{C}$ into soil organic matter fractions and the respired $\mathrm{CO}_{2}$}

Dynamics of added label were monitored in bulk soil, microbial biomass, $\mathrm{CO}_{2}$ respiration and exC. In general, $\mathrm{C}_{\mathrm{mic}}$ showed the highest proportions of label-derived $\mathrm{C}$ (RSA) followed by $\mathrm{CO}_{2}$; the lowest RSA were found in exC (Fig. 1).

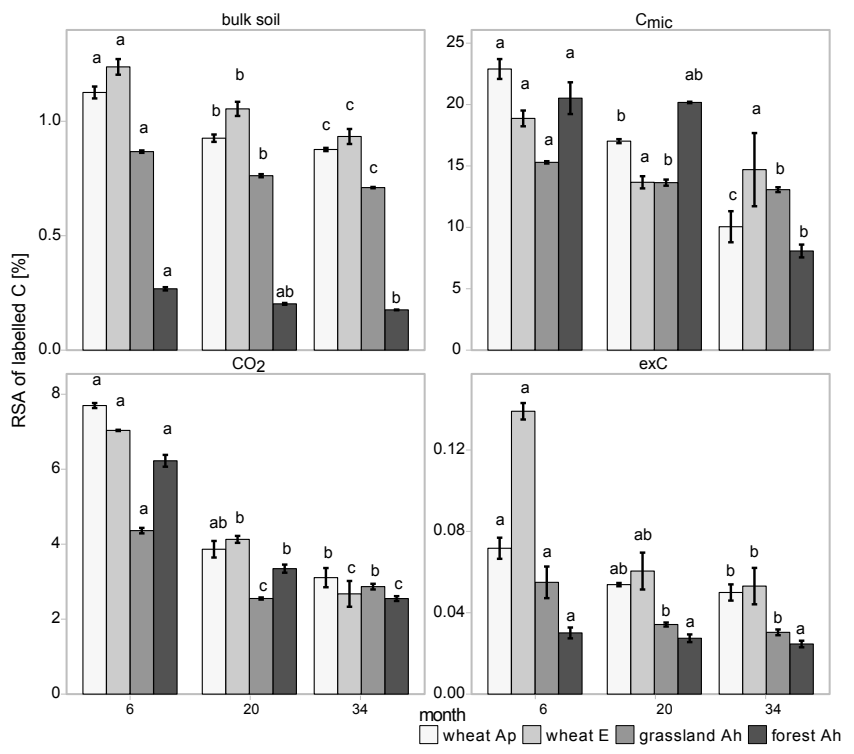

Figure 1. Fraction of labelled $\mathrm{C}$ in total $\mathrm{C}$ of bulk soil $\mathrm{C}$, microbial biomass $\left(\mathrm{C}_{\text {mic }}\right)$, respired $\mathrm{CO}_{2}$, and $\mathrm{K}_{2} \mathrm{SO}_{4}$-extractable carbon (exC) of the wheat $\mathrm{Ap}$ and $\mathrm{E}$, grassland $\mathrm{Ah}$ and forest $\mathrm{Ah}$ after 6, 20 and 34 months of incubation. Different letters indicate significant differences $(p<0.05)$ within one treatment over time. Means \pm standard error $(n=3)$.

After 6 months of incubation 1.1, 1.2, 0.9 and $0.3 \%$ of the bulk $\mathrm{C}$ pool of the wheat Ap, wheat $\mathrm{E}$, grassland $\mathrm{Ah}$ and forest $\mathrm{Ah}$, respectively, were derived from labelled $\mathrm{C}$. Between 6 and 34 months of incubation about 30, 20 and $40 \%$ of label derived $\mathrm{C}$ was lost from the bulk soil $\mathrm{C}$ pool in wheat, grassland and forest incubations respectively, while total $\mathrm{C}$ concentrations did not change significantly (Fig. 1). The $\mathrm{C}_{\mathrm{mic}}$ of the wheat Ap, E grassland Ah and forest Ah were 230, 140,851 and $622 \mu \mathrm{gC} \mathrm{g}^{-1} \mathrm{dw}$ soil after 6 months of incubation (Fig. 2). This corresponds to an increase of 8, 40 and $35 \%$ of $\mathrm{C}_{\text {mic }}$ compared to the initial content before glucose addition in wheat $\mathrm{Ap}$, wheat $\mathrm{E}$ and forest $\mathrm{Ah}$, respectively. The grassland $\mathrm{Ah}$ lost $8 \%$ of $\mathrm{C}_{\text {mic }}$ after incubation started (Fig. 2). After 6 months, 23, 19, 15 and $21 \%$ of the $\mathrm{C}_{\text {mic }}$ in the wheat Ap, E, grassland and forest incubations were derived from the added label and label contribution decreased during further incubation. Also, total $\mathrm{C}_{\text {mic }}$ decreased during incubation, with the exception of the forest Ah soil (Fig. 1). The $\mathrm{CO}_{2}$ emitted from the incubated soils showed similar behaviour, i.e. decreasing production of $\mathrm{CO}_{2}$ accompanied with decreasing label contribution. However, the contribution of added label to $\mathrm{CO}_{2}$ production (4-8\%) was much lower than for microbial biomass (15-25\%; Fig. 1). The exC only showed marginal proportions of label-derived $\mathrm{C}$ (0.03-0.14\%), which also decreased with increasing incubation time.

When regarding the partitioning of labelled $\mathrm{C}$ into the different investigated soil fractions (Fig. 3), the bulk soil contained between 26.5 and $42.8 \%$ of the added label after 


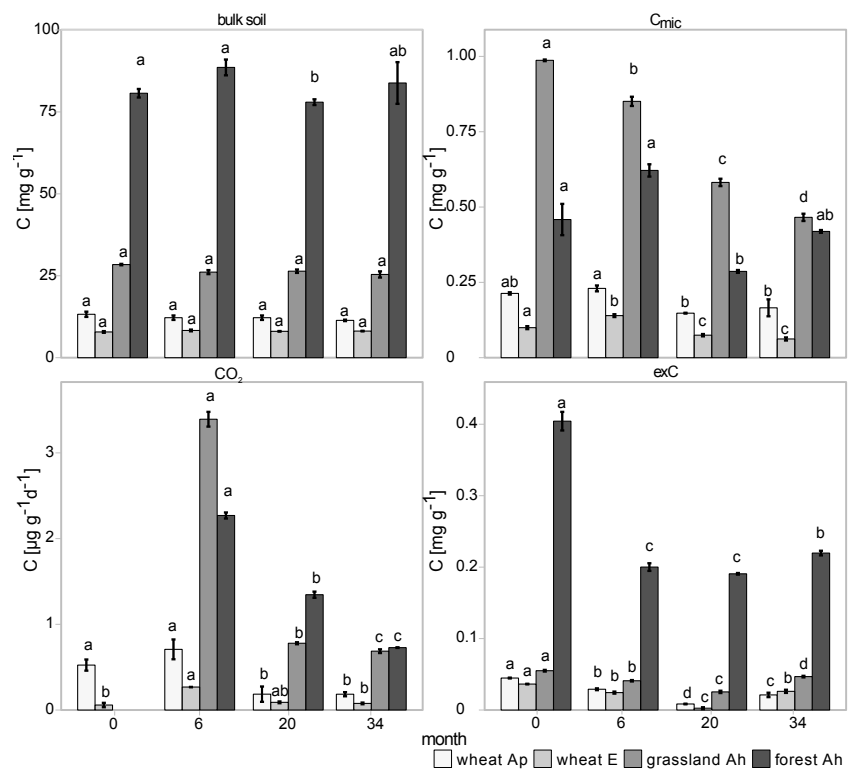

Figure 2. Concentrations of bulk soil $\mathrm{C}$, microbial biomass $\mathrm{C}$ $\left(\mathrm{C}_{\text {mic }}\right)$, respired $\mathrm{CO}_{2}$ and $\mathrm{K}_{2} \mathrm{SO}_{4}$-extractable carbon (exC) in wheat $\mathrm{Ap}$ and $\mathrm{E}$, grassland $\mathrm{Ah}$ and forest Ah before (0) and after 6, 20 and 34 months of incubation. Different letters indicate significant differences $(p<0.05)$ within one treatment over time. Mean and standard error $(n=3)$.

6 months of incubation. The label continually decreased in all treatments with incubation time due to $\mathrm{CO}_{2}$ losses. The partitioning of labelled $\mathrm{C}$ to the sugar pool and $C_{\text {mic }}$ was of comparable size but showed a more pronounced decrease with ongoing incubation time in the $C_{\text {mic }}$ pool as compared to sugars. Less than $1 \%$ of the added label was found in the exC.

\subsection{Incorporation of added label into sugars}

Around $9 \%$ of bulk soil C in the wheat Ap, E and grassland $\mathrm{Ah}$ incubations and $5 \%$ in forest $\mathrm{Ah}$ were attributed to sugars. The relative proportions of the individual sugars were quite similar among the investigated soil horizons (Table 1). The dominant sugar in all types of land use was glucose (glc), followed by the hexoses gal and man and the pentoses ara and xyl. The desoxyhexoses (fuc, rha) showed smallest contributions, with the exception of fuc in forest soil, which occurred in similar proportions as ara. After 6 months of incubation, label-derived $\mathrm{C}$ incorporated into all sugars (with the exception of glucose) was 1.9 and $1 \%$ in the incubated wheat Ap and $\mathrm{E}$ horizons, respectively and this proportion decreased during further incubation (data not shown). In contrast, in the grassland and forest soils, label-derived $\mathrm{C}$ increased during incubation from 1.2 and $0.6 \%$ after 6 months to 1.4 and $0.8 \%$. Apart from glc, label-derived microbial sugars were mainly composed of man $(\sim 12 \%)$ and gal $(\sim 9 \%)$ and smaller proportions of rha $(\sim 6 \%)$, fuc, ara and xyl $(\sim 3 \%$; Table 2).

\subsection{Dynamics of label-derived $\mathrm{C}$ of the individual sugars}

Glc showed highest contribution of labelled $\mathrm{C}$ throughout the experiment. Values decreased from $6.4,6.2,6.2$, and $2.3 \%$ after 6 months to $4.2,3.5,3.1$ and $1.4 \%$ in wheat Ap, E, grassland $\mathrm{Ah}$ and forest $\mathrm{Ah}$, respectively (data not shown). The trends for the other sugars were quite similar in the different incubated soils (Fig. 4a-d): man and fuc showed a decreasing trend in label contribution, whereas the label contribution increased in rha and gal during the first weeks of incubation, but did not change afterwards. Man and rha showed contributions of labelled $\mathrm{C}$ between 0.3 and $1.9 \%$ for the different incubations after 6 months, followed by gal and fuc $(0.3-1.5 \%$, Fig. 4$)$. The mainly plant-derived sugars ara and xyl showed considerable contribution of labelderived $\mathrm{C}$ of about 0.2 and $0.6 \%$ after 6 months, although to a lesser extent than the "microbial sugars" (man, gal, rha). The contribution of labelled $\mathrm{C}$ to ara slightly increased during the whole incubation time in all but the forest soil, where an initial increase was followed by a decrease. The contributions of labelled $\mathrm{C}$ to $\mathrm{xyl}$ increased weakly in both wheat soil horizons, whereas it was constant in the grassland and forest soil. Non-linear regression analysis was performed on RSA values to analyse the kinetics of soil sugar turnover. Mono-exponential (Eq. 5) as well as bi-exponential (Eq. 6) functions were tested to describe the dynamics of soil sugars. AIC values were used to identify the best fit (Table S1 in the Supplement). No clear pattern was observed whether dynamics of individual sugars or of different soils were characterized by mono or bi exponential models (Table S2). Best fits for each sugar and land use are shown in Fig. 4. In the cases where a decaying label contribution was observed, the MRT of the sugar $\mathrm{C}$, calculated from the nonlinear regression analysis with Eqs. (5) and (6), ranged from a few months for the labile pool over several years (1-365 years), representing an intermediate pool (Table 3 ). The highest (5957 years) was calculated for gal in the wheat Ap.

\section{Discussion}

\subsection{Glucose incorporation into soil $\mathrm{C}$ and microbial biomass $\mathbf{C}$}

Our aim was to investigate the transformation and stabilization processes of the added labelled $\mathrm{C}$ during the first 3 years after substrate addition. After 6 months of incubation, the bulk soil C pool still contained 25 to $42 \%$ of the added label, which is in line with findings of previous studies, where less than $50 \%$ of added glucose were recovered after 1 or 2 months of incubation (Saggar, 1999; Murayama, 1988). As an easily accessible $\mathrm{C}$ source, glucose stimulates microbial 
Table 1. Sugar composition of the organic matter in the wheat Ap, wheat E, grassland Ah and forest Ah soils before incubation. Means \pm standard error, $n=3$.

\begin{tabular}{lrrrrrrrrr}
\hline & Depth [cm] & \multicolumn{2}{c}{ SugarC [\%] } & & \multicolumn{5}{c}{ Distribution of sugars [\%] } \\
\hline & & & ara & xyl & fuc & rha & gal & man & glc \\
\hline wheat Ap & $0-30$ & $8 \pm 0.1$ & $14 \pm 0.9$ & $15 \pm 0.3$ & $4 \pm 0.2$ & $7 \pm 0.1$ & $17 \pm 0.1$ & $15 \pm 0.2$ & $29 \pm 0.6$ \\
wheat E & $30-45$ & $7 \pm 0.8$ & $13 \pm 0.2$ & $13 \pm 0.5$ & $4 \pm 0.3$ & $8 \pm 0.1$ & $17 \pm 0.0$ & $15 \pm 0.1$ & $31 \pm 0.5$ \\
grassland Ah & $0-10$ & $8 \pm 0.6$ & $14 \pm 0.2$ & $13 \pm 0.2$ & $5 \pm 0.1$ & $9 \pm 0.1$ & $16 \pm 0.2$ & $14 \pm 0.5$ & $29 \pm 0.6$ \\
forest Ah & $0-10$ & $6 \pm 0.3$ & $7 \pm 0.2$ & $12 \pm 0.2$ & $7 \pm 0.3$ & $5 \pm 0.2$ & $14 \pm 0.7$ & $18 \pm 0.3$ & $36 \pm 0.6$ \\
\hline
\end{tabular}

Table 2. Relative distribution of total label derived sugar C [wt \%] among different sugars after 6 and 24 months of incubation (means \pm standard error; $n=3)$. Significant differences $(p<0.05)$ between the two sampling times are indicated by an asterisk.

\begin{tabular}{lcc|cc|cc|cc}
\hline & \multicolumn{2}{c}{ wheat Ap } & \multicolumn{2}{c|}{ wheat E } & \multicolumn{2}{c|}{ grassland Ah } & \multicolumn{2}{c}{ forest Ah } \\
\hline Sugar & $6 \mathrm{~m}$ & $24 \mathrm{~m}$ & $6 \mathrm{~m}$ & $24 \mathrm{~m}$ & $6 \mathrm{~m}$ & $24 \mathrm{~m}$ & $6 \mathrm{~m}$ & $24 \mathrm{~m}$ \\
\hline fuc & $4.0 \pm 1.1$ & $3.7 \pm 1.9$ & $2.7 \pm 0.7$ & $3.0 \pm 0.4$ & $1.3 \pm 0.0$ & $1.4 \pm 0.1$ & $2.1 \pm 0.1$ & $3.0 \pm 0.2^{*}$ \\
ara & $2.7 \pm 0.1$ & $3.4 \pm 0.1^{*}$ & $3.3 \pm 0.1$ & $4.2 \pm 0.0^{*}$ & $2.5 \pm 0.2$ & $2.8 \pm 0.2$ & $0.9 \pm 0.0$ & $1.4 \pm 0.0^{*}$ \\
rha & $8.7 \pm 1.2$ & $9.7 \pm 2.6$ & $7.9 \pm 1.0$ & $9.8 \pm 0.6$ & $4.6 \pm 0.1$ & $5.6 \pm 0.1^{*}$ & $1.5 \pm 0.1$ & $2.3 \pm 0.1^{*}$ \\
gal & $9.9 \pm 0.1$ & $12.6 \pm 0.2^{*}$ & $10.1 \pm 0.6$ & $13.2 \pm 0.5^{*}$ & $6.0 \pm 0.1$ & $7.6 \pm 0.0^{*}$ & $5.1 \pm 0.3$ & $8.0 \pm 0.2^{*}$ \\
glc & $60.7 \pm 2.9$ & $54.6 \pm 5.6$ & $61.0 \pm 2.8$ & $52.8 \pm 1.4^{*}$ & $75.1 \pm 0.3$ & $70.3 \pm 1.0^{*}$ & $78.5 \pm 1.1$ & $66.8 \pm 1.3^{*}$ \\
xyl & $2.2 \pm 0.2$ & $2.7 \pm 0.2^{*}$ & $2.8 \pm 0.3$ & $3.1 \pm 0.1$ & $1.9 \pm 0.1$ & $2.0 \pm 0.4$ & $2.5 \pm 0.2$ & $4.0 \pm 0.3^{*}$ \\
man & $11.8 \pm 0.7$ & $13.3 \pm 0.6^{*}$ & $12.1 \pm 0.4$ & $14.0 \pm 0.3^{*}$ & $8.8 \pm 0.2$ & $10.3 \pm 0.3^{*}$ & $9.5 \pm 0.5$ & $14.3 \pm 0.4^{*}$ \\
\hline
\end{tabular}

growth in soil and leads to increased initial respiration, especially of newly added C (Schneckenberger et al., 2008). After 6 months, between 15 and $23 \%$ of the $\mathrm{C}_{\text {mic }}$ was derived from the added label and the proportion decreased during further incubation (Fig. 1). As the living microbial biomass actively takes up and incorporates the added glucose, it is expected to have a higher $\mathrm{C}$ turnover than the bulk soil $\mathrm{C}$ pool. However, the contribution of added label to microbial biomass $\mathrm{C}$ was quite high and remained at a high level during the whole incubation (resulting in label contribution of up to $15 \%$ after 30 months, Fig. 1). This could be related to the fact that some microorganisms, especially K-strategists, are able to store glucose as an intracellular reservoir (as glycogen; Blagodatskaya et al., 2007, Wilson et al., 2010). This is contradicted by the fact that label partitioning into the sugar pool decreases more slowly than to the $\mathrm{C}_{\text {mic }}$ pool and that the relative importance of glc as compared to the other sugars remains fairly constant (Fig. 3). Moreover our data on decreasing microbial biomass and decreasing $\mathrm{C}$ mineralization over time indicate substrate limitation. It seems unlikely that high amounts of glucose are stored within the microbial biomass under these conditions. It is more likely that the microbial community maintained their metabolic capacity by feeding on dead microbial biomass as was also shown by Kindler et al. (2006) or Guenet et al. (2011). This would be in line with the slow decline of glucose-derived label contribution in the microbial biomass, which was similarly shown by Gunina et al. (2014). Their data indicate that substrates entering citric acid cycle are preferentially respired whereas substrates, like glucose, entering glycolysis are preferentially incorporated into microbial biomass, i.e. recycled. Corroborating this, our data indicate that considerable amounts of "old" SOM are used for energy gain (mineralization) rather than recent microbial necromass as the RSA of $\mathrm{CO}_{2}$ is much lower than that of the microbial biomass throughout the experiment. It is probable that the constant mixing of the soil during the biweekly sampling events increased the accessibility also of "old" soil C sources. This is in line with Lamparter et al. (2009) and Joergensen and Raubuch (2003) who showed that mixing and rewetting improve the $\mathrm{C}$ availability for microbial uptake.

Together with the observed long MRT of sugar $\mathrm{C}$ our data indicate that after high initial losses of added $\mathrm{C}$ substrate that has often been observed after glucose (Schneckenberger et al., 2008; Saggar et al., 1999), or microbial necromass addition (Miltner et al., 2012; Kindler et al., 2006) the microbial biomass recycled $\mathrm{C}$ substrates efficiently and with only minimal C losses.

\subsection{Effect of incubation on sugar composition}

The relative amounts of the investigated sugars did not differ substantially among the different soils investigated here. Sugars made up around $8 \%$ of the $\mathrm{C}$ in arable and grassland soils, in the forest soil the proportion was smaller with 6\%, corroborating earlier findings (Lowe and Brown, 1975; Rumpel and Dignac, 2006; Guggenberger et al., 1994; Cheshire, 1979). Furthermore, the general sugar distribution 
Table 3. Estimated apparent MRT and pool size of sugars in the wheat Ap, wheat E, grassland Ah and forest Ah incubations. * reflects initial exponential growing pools.

\begin{tabular}{|c|c|c|c|c|c|}
\hline & & \multicolumn{2}{|c|}{ labile pool } & \multicolumn{2}{|c|}{ intermediate/stable pool } \\
\hline & & years & $\begin{array}{l}\text { pool size } \\
{\left[\mathrm{mg} \mathrm{g}^{-1}\right]}\end{array}$ & years & $\begin{array}{l}\text { pool size } \\
{\left[\mathrm{mg} \mathrm{g}^{-1}\right]}\end{array}$ \\
\hline \multirow[t]{4}{*}{ wheat Ap } & fuc & - & - & 44 & 0.30 \\
\hline & rha & 0.02 & $0.84^{*}$ & - & - \\
\hline & gal & 0.07 & $0.17^{*}$ & 5957 & 0.67 \\
\hline & $\operatorname{man}$ & - & - & 21 & 0.82 \\
\hline \multirow[t]{4}{*}{ wheat E } & ara & - & - & 82 & 0.16 \\
\hline & xyl & 0.2 & 0.07 & - & - \\
\hline & fuc & 0.2 & 0.11 & 71 & 0.07 \\
\hline & $\operatorname{man}$ & 0.6 & 0.17 & 79 & 0.50 \\
\hline \multirow[t]{5}{*}{ grassland Ah } & ara & 0.1 & $0.15^{*}$ & & \\
\hline & fuc & - & - & 79 & 0.15 \\
\hline & rha & - & - & 231 & 0.54 \\
\hline & gal & 0.1 & 0.32 & - & - \\
\hline & $\operatorname{man}$ & 0.04 & $0.25^{*}$ & 15 & 1.03 \\
\hline \multirow[t]{6}{*}{ forest $\mathrm{Ah}$} & ara & 1.20 & 0.26 & 3 & 0.37 \\
\hline & xyl & 0.05 & $0.45^{*}$ & 34 & 0.34 \\
\hline & fuc & 0.6 & 0.24 & 82 & 0.06 \\
\hline & rha & - & - & 365 & 0.19 \\
\hline & gal & 0.06 & $0.44^{*}$ & 54 & 0.66 \\
\hline & man & - & - & 45 & 1.25 \\
\hline
\end{tabular}

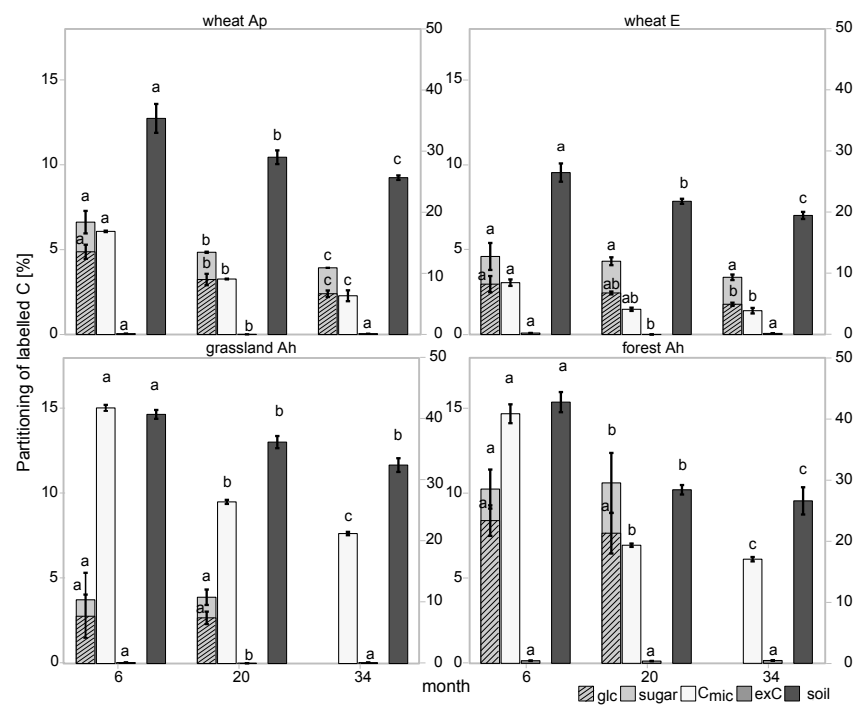

Figure 3. Partitioning of the labelled $\mathrm{C}$ into microbial biomass $\left(C_{\text {mic }}\right), \mathrm{K}_{2} \mathrm{SO}_{4}$-extractable carbon (exC), glc and sum of all sugars (left axis) and bulk soil (right axis) in wheat Ap and E, grassland Ah and forest Ah after 6, 20 and 34 months of incubation. Different letters indicate significant differences $(p<0.05)$ within one treatment over time. Means \pm standard error $(n=3)$.

pattern did not differ significantly among the investigated types of land use: the dominant sugar was glc, followed by man and gal. The contribution of the plant-derived sugars xyl and ara was somewhat smaller and only minimum proportions of rha and fuc were found. The only variation was observed in the forest soil, where ara was half and fuc was twice the proportion observed in the other soils. The general distribution of sugars in the arable and grassland soils were concordant with studies by Muramaya (1988), Derrien et al. (2007), Creamer et al. (2012).

There was a close correlation between total and labelled sugar content for the microbial sugars $(R=0.69$, data not shown, no correlation for ara and xyl), indicating that the dynamics before and during incubation were basically the same with the exception of plant input. During the incubation highest synthesis rates were observed for man and gal, followed by rha and fuc, whereas new synthesis of xyl and ara was less. These findings are similar to those of Muramaya (1988) and Derrien et al. (2007). The (small) new synthesis of ara and xyl can probably be traced back to fungi and yeast, as shown by Coelho et al. (1988) and Cheshire et al. (1976). As supply by plant debris or root exudates was missing the dynamics of ara and xyl were obviously controlled by the microbial community during the incubation.

Proportions of labelled $\mathrm{C}$ ranged between 0.6 to $1.9 \%$ of the individual sugars (without glc) after 6 months of incubation. During further incubation, the proportion of the added label in the sugar pool of both wheat soil incubations de- 

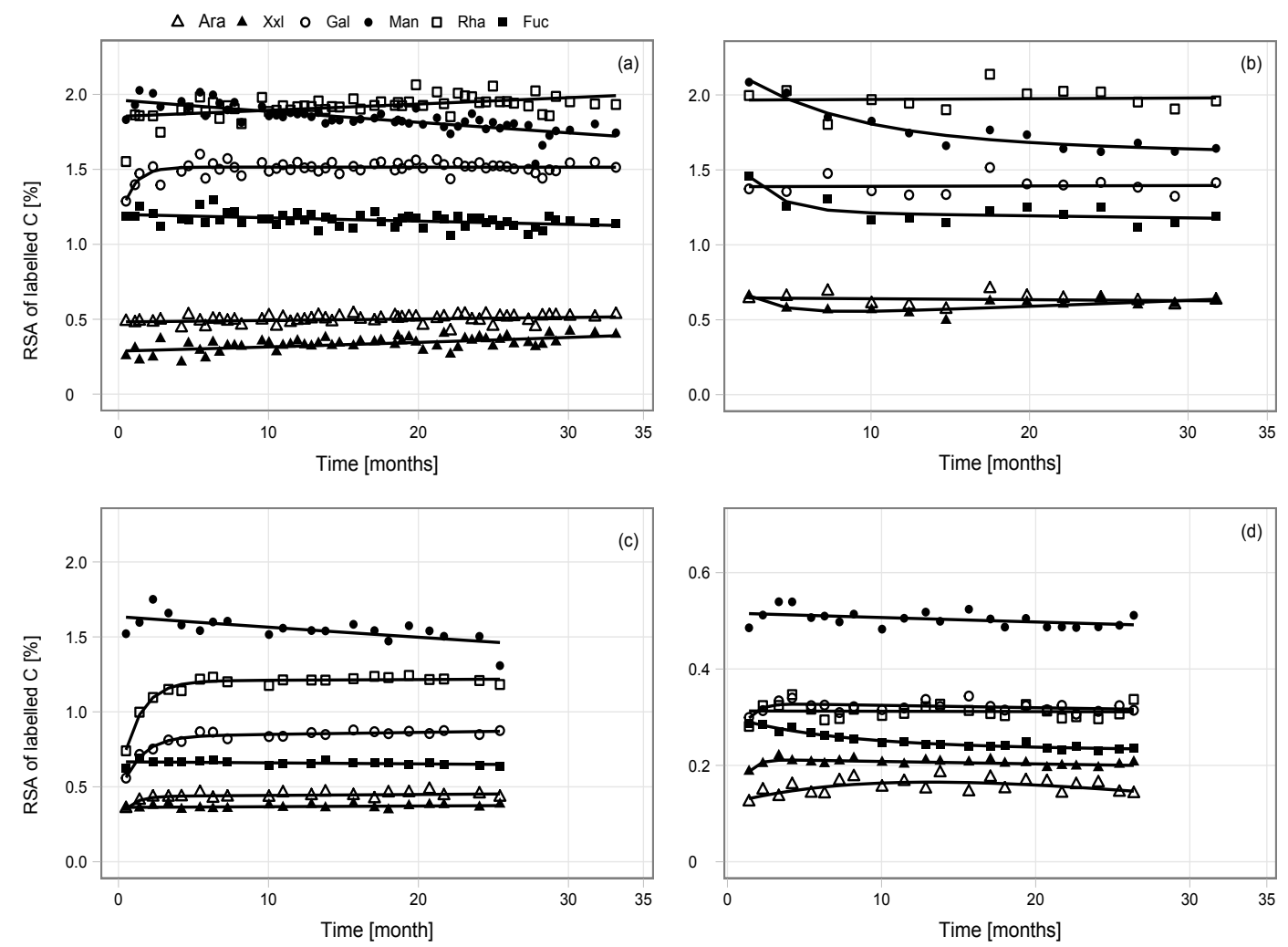

Figure 4. RSA of labelled $C$ of individual sugars in the incubated soil samples. Lines show the fit of the observed data. a) wheat Ap, b) wheat E horizon of c) grassland and d) forest soil. The parameters of the exponential equations are given in Table S2.

creased very slightly by $5 \%$, whereas it increased in the grassland and forest soil incubations. Additionally, an increase of total sugar amounts occurred in grassland and forest soil incubations, whereas in the wheat soil the amounts decreased by $20 \%$ (data not shown). This suggests that in both wheat soil incubations, due to limited C supply, recycling dominated the sugar $\mathrm{C}$ dynamics as the microbial community used all available $\mathrm{C}$-sources. Thus, the contributions of labelled C decreased, as greater amounts of soil organic $\mathrm{C}$ (and not only the recently added glucose) were used in microbial metabolism. This showed how effectively the microbial community converts $\mathrm{C}$ compounds and responds to changing conditions. This corresponds with studies by Salomé et al. (2010), Kramer and Gleixner (2006, 2008), Creamer et al. (2014) who showed that microorganisms change their feeding strategies from recent to more old SOM compounds depending on $\mathrm{C}$ availability and quality.

The increasing contribution of label $\mathrm{C}$ to the sugar pool in the SOM-rich grassland soil can be related to the fact that a considerably larger soil C-pool was initially accessible for microbial metabolism. In the grassland soil, this corresponds with less label-derived $\mathrm{C}$ in microbial biomass and $\mathrm{CO}_{2}$ as compared to the soils under other land use. However, with increasing incubation time more labelled $\mathrm{C}$ was incorporated into the sugar pool because the amount of accessible "old"
C decreased continuously and thus glucose, bound to SOM is successively used. In the forest soil, microbial biomass and $\mathrm{CO}_{2}$ contained more label-derived $\mathrm{C}$ as compared to the grassland soil. This suggests that the added labelled $\mathrm{C}$ source was predominantly used by the microbial biomass because most of the "old" C was not accessible for metabolism, i.e. was stabilized. Waldrop and Firestone (2004) found that the microbial community preferentially incorporated added easily degradable $\mathrm{C}$ compounds in low-quality SOM soils. Forest litter is enriched in aromatic, phenolic and alkyl-C, which might be less attractive for microorganisms (KögelKnabner, 2002; Nierop et al., 2001; Helfrich et al., 2006). Therefore, the added glucose provided an easily utilizable C source compared to the SOM in the forest soil and was preferentially used by the microbial community as reflected by the high label contribution to $\mathrm{C}_{\mathrm{mic}}$ and $\mathrm{CO}_{2}$ in relation to the bulk soil label contribution (Figs. 1 and 3). Additionally, in the acid forest soil, decomposition occurred mainly in the humus layer, whereas in arable or grassland, decomposition occurred directly in mineral soil (Kögel-Knabner et al., 1988; Helfrich et al., 2006; Guggenberger and Zech, 1994). Therefore, the $C$ incorporation seems to be lower than in arable and grassland soils, especially for easily utilizable compounds. Together with litter quality the reduced microbial activity promote the effect of SOM stabilization in forest 
soils. To sum up, the accessibility of $\mathrm{C}$ compounds control the effect of recycling and stabilization: both recycling and stabilization are important processes in forest soils. However, for arable soils and grassland, recycling seems to dominate the $\mathrm{C}$ dynamics.

\subsection{Sugar dynamics}

Several studies aimed at differentiating between sugar pools, based on incubations for up to 1 year (Muramaya, 1988; Derrien et al., 2007), but conclusions about factors controlling the long-term decay kinetics of soil sugars were not possible, presumably due to the short duration of the experiment and a low number of sampling times. Hence, the intended target of our study was to investigate the long-term dynamics of sugars, based on highly frequent sampling during 3 years of incubation to identify multiple decay pools. However, the apparent high importance of recycling, which was shown by increasing label incorporation (Fig. 4) and as a consequence positive k-values (Table S2) impeded the differentiation of several pools of the investigated sugars. This displays the drawback of the experiment, as recycling of the added $\mathrm{C}$ substrate influenced the decay dynamics. Ara and xyl, as supposedly plant-derived sugars, showed a considerable denovo synthesis by microorganisms and thus the differentiation into plant-derived sugars subject only to stabilization and microbial sugars, subject to stabilization and recycling was difficult. In our study the sugar dynamics were described by mono and bi-exponential functions. An incubation study by Derrien et al. (2007), however, used bi-exponential decay functions to describe sugar decay dynamics with a constant pool $(k=0)$ as it apparently remained undecomposed throughout the incubation. However, in our experiment, the contribution of labelled $\mathrm{C}$ to the individual sugars changed throughout the incubation even though very slightly, thus the assumption of a constant pool would not correspond to our data. A labile pool could be determined for rha and gal in the wheat Ap; for xyl, fuc and man in wheat $\mathrm{E}$ and for ara, xyl, fuc and gal in the forest Ah (Table 3). The MRT ranged between a few days and up to 2 months, depending on the different investigated soils (Table 3). These data agree well with the study by Derrien et al. (2007). They reported MRT of 17 days for the labile sugar pool. The MRT of the stable microbial-derived sugars ranged up to 365 years. The highest MRT was estimated for gal in the wheat Ap with 5957 years. This is even more surprising because interactions of sugars with the soil matrix are reported as less important for their fate (Gunina and Kuzyakov, 2015) supporting the idea of recycling and not stabilization as dominant process. Therefore, such high values can only be explained by a high contribution of substrate recycling and corresponds with the observed high proportions of labelled $\mathrm{C}$ in the microbial biomass throughout the experiment. From pure culture studies it is known that $5 \%$ of the dry weight of prokaryotic cells consist of polysaccharides (Madigan et al., 2003).
Thus, the label contribution of the soil sugars to microbial biomass is relatively low and turnover of microbial biomass thus masks changes in sugars over time. Additionally, with chloroform-fumigation extraction mainly $\mathrm{C}$ of the cytoplasm is determined, whereas more complex structures in cell walls are probably hardly extracted (Joergensen, 1996; Apostel et al., 2015). This may lead to an overestimation of the dynamics of labelled $\mathrm{C}$ in microbial biomass as cell walls probably are neither strongly labelled at the beginning of the experiment, nor do they cycle as fast as the other pools of the microbial biomass (Glaser and Gross, 2005; Miltner et al., 2009; Malik et al., 2013).

Apart from long-term label incorporation trends (discussed below), all sugars show small sinus-like fluctuations (Fig. 4, most pronounced for man). One could speculate that this phenomenon might be related to shifts in the microbial community, which in turn increased resource availability, in which extracellular enzymes metabolites or lysed cells of one functional group increase substrates for another (Blagodatskaya and Kuzyakov, 2008; Mau et al., 2015).

More importantly, the similar behaviour of fuc and man on the one hand and gal and rha on the other is of interest (Fig. 4). While fuc and man showed highest label contribution directly at the beginning of the experiment and exhibited remarkable decline afterwards, label contribution in rha and gal increased during the first weeks of the experiment and reached steady state after 4 months. These different dynamics could be related with different strategies of microbial groups: fuc and man could be representative for r-strategist that quickly acquire new substrates but are forced into dormancy if nutrient supply becomes limited, whereas K- strategists could be represented by the dynamics of gal and rha. These groups only slowly profit from the added labelled nutrients, but are able to live on these resources for a very long time. One could speculate whether the slow increase in gal and rha is due to recycling of starving r-strategist or results from the use of stored glucose (Blagodatskaya et al., 2007) acquired at the beginning of the experiment.

Another explanation for the different dynamics could be different provinces of the two pools. For example exopolysaccharides are part of microbial biofilms and are composed mainly of fuc, gal, man and glc (Freitas et al., 2011; Neu and Lawrence, 1997). On the other hand, lipopolysaccharides (LPS) are part of the outer cell membrane and are composed of gal, rha and man monosaccharide units (Lengeler et al., 1999). If the dynamics of fuc and man would be representative for the dynamics of exopolysaccharides of microbial biofilms, this would indicate that they quickly incorporate available substrate but rely on "old" SOM-derived $\mathrm{C}$ when the added substrate is no longer available. Likewise, the gal and rha dynamics could be characteristic for LPS, indicating that these underlie a repeated recycling within the microbial biomass pool: the labelled substrate is only slowly incorporated into the LPS pool but is then retained there for long times. 


\section{Conclusions}

The observed high MRT for sugars indicate that recycling dominates sugar dynamics in soil and that the high importance of recycling is not substantially affected by soil C content. Thus, MRT of substance classes, as stated in many previous studies, has to be taken with care as they do not necessarily reflect the MRT of these substances but rather the MRT of the pool-derived C, which may be frequently recycled within or outside of this pool.

Further, the persistently higher contribution of added label to microbial biomass as compared to $\mathrm{CO}_{2}$ production indicates that substrate recycling is very effective in the long term. Two different patterns of tracer dynamics could be identified for different sugars: fuc and man showed highest label contribution at the beginning of the incubation with a subsequent slow decline. Gal and rha, on the other hand were characterized by slow label incorporation with subsequently constant levels, indicating that the dynamics of these sugars are dominated by substrate recycling.

\section{The Supplement related to this article is available online at doi:10.5194/bg-12-5929-2015-supplement.}

Acknowledgements. This research was funded by the Deutsche Forschungsgemeinschaft (DFG). We gratefully thank Reinhard Langel for his technical assistance and Iris Ficht and Viola Lauenstein for assistance in the laboratory.

Edited by: Y. Kuzyakov

This open-access publication was funded by the University of Göttingen.

\section{References}

Akaike, H.: Information theory and an extension of the maximum likelihood principle, in: Selected Papers of Hirotugu Akaike, edited by: Parzen, E., Tanabe, K., and Kitagawa, G., Springer Series in Statistics, Springer New York, 1998.

Amelung, W., Cheshire, M. V., and Guggenberger, G.: Determination of neutral and acidic sugars in soil by capillary gas-liquid chromatography after trifluoroacetic acid hydrolysis, Soil Biol. Biochem., 28, 1631-1639, 1996.

Amelung, W., Brodowski, S., Sandhage-Hofmann, A., and Bol, R.: Combining Biomarker with Stable Isotope Analyses for Assesing the Transformation and Turnover of Soil Organic Matter, in: Advances in Agronomy, Vol 100, Adv. Agron, Elsevier Acacemic Press Inc, 155-250, 2008.

Apostel, C., Dippold, M., and Kuzyakov, Y.: Biochemistry of hexose and pentose transformations in soil analyzed by positionspecific labeling and 13C-PLFA, Soil Biol. Biochem., 80, 199208, doi:10.1016/j.soilbio.2014.09.005, 2015.
Basler, A. and Dyckmans, J.: Compound-specific delta C-13 analysis of monosaccharides from soil extracts by highperformance liquid chromatography/isotope ratio mass spectrometry, Rapid Commun. Mass Spectrom., 27, 2546-2550, doi:10.1002/rcm.6717, 2013.

Blagodatskaya, E. and Kuzyakov, Y.: Mechanisms of real and apparent priming effects and their dependence on soil microbial biomass and community structure: critical review, Biol. Fertil. Soils, 45, 115-131, doi:10.1007/s00374-008-0334-y, 2008.

Blagodatskaya, E. V., Blagodatsky, S. A., Anderson, T.-H., and Kuzyakov, Y.: Priming effects in Chernozem induced by glucose and $\mathrm{N}$ in relation to microbial growth strategies, Appl. Soil Ecol., 37, 95-105, doi:10.1016/j.apsoil.2007.05.002, 2007.

Brookes, P., Landman, A., Pruden, G., and Jenkinson, D. S.: Chloroform fumigation and the release of soil nitrogen: A rapid direct extraction method to measure microbial biomass nitrogen in soil, Soil Biol. Biochem., 17, 837-842, doi:10.1016/00380717(85)90144-0, 1985.

Cheshire, M. V.: Nature and origin of carbohydrates in soils, Academic Pr, London, 216 pp., 1979.

Cheshire, M. V., Greaves, M. P., and Mundie, C. M.: The effect of temperature on the microbial transformation of $\left({ }^{14} \mathrm{C}\right)$ glucose during incubation in soil, J. Soil Sci., 27, 75-88, doi:10.1111/j.1365-2389.1976.tb01978.x, 1976.

Cheshire, M. V., Inkson,, R. H. E., Mundie, C. M., and Sparling, G. P.: Studies on the rate of decomposition of plant residues in soil by following the changes in sugar components, J. Soil Sci., 39, 227-236, doi:10.1111/j.1365-2389.1988.tb01209.x, 1988.

Coelho, R. R., Linhares, L. F., and Martin, J. P.: Sugars in hydrolysates of fungal melanins and soil humic acids, Plant Soil, 106, 127-133, doi:10.1007/BF02371204, 1988.

Creamer, C. A., Filley, T. R., Olk, D. C., Plante, A., Peltre, C., Top, S. M., and Boutton, T. W.: Degree of woody encroachment into grasslands controls soil carbohydrate and amino compound changes during long term laboratory incubation, Org. Geochem., 52, 23-31, doi:10.1016/j.orggeochem.2012.08.005, 2012.

Creamer, C. A., Jones, D. L., Baldock, J. A., and Farrell, M.: Stoichiometric controls upon low molecular weight carbon decomposition, Soil Biol. Biochem., 79, 50-56, doi:10.1016/j.soilbio.2014.08.019, 2014.

Deleens, E., Cliquet, J. B., and Prioul, J. L.: Use of 13 C and 15 N Plant Label Near Natural Abundance for Monitoring Carbon and Nitrogen Partitioning, Aust. J. Plant Physio., 21, 133-146, doi:10.1071/PP9940133, 1994.

Derrien, D. and Amelung, W.: Computing the mean residence time of soil carbon fractions using stable isotopes: impacts of the model framework, Eur. J. Soil Sci., 62, 237-252, doi:10.1111/j.1365-2389.2010.01333.x, 2011.

Derrien, D., Marol, C., Balabane, M., and Balesdent, J.: The turnover of carbohydrate carbon in a cultivated soil estimated by 13C natural abundances, Eur. J. Soil Sci., 57, 547-557, 2006.

Derrien, D., Marol, C., and Balesdent, J.: Microbial biosyntheses of individual neutral sugars among sets of substrates and soils, Geoderma, 139, 190-198, 2007.

Dyckmans, J. and Flessa, H.: Influence of tree internal nitrogen reserves on the response of beech (Fagus sylvatica) trees to elevated atmospheric carbon dioxide concentration, Tree Physiol., 22, 41-49, doi:10.1093/treephys/22.1.41, 2002. 
Engelking, B., Flessa, H., and Joergensen, R. G.: Formation and use of microbial residues after adding sugarcane sucrose to a heated soil devoid of soil organic matter, Soil Biol. Biochem., 40, 97105, doi:10.1016/j.soilbio.2007.07.009, 2008.

Fontaine, S., Mariotti, A., and Abbadie, L.: The priming effect of organic matter: a question of microbial competition?, Soil Biol. Biochem., 35, 837-843, doi:10.1016/S0038-0717(03)00123-8, 2003.

Freitas, F., Alves, V. D., Torres, C. A., Cruz, M., Sousa, I., Melo, M. J., Ramos, A. M., and Reis, M. A.: Fucose-containing exopolysaccharide produced by the newly isolated Enterobacter strain A476 DSM 23139, Carbohyd. Polym., 83, 159-165, doi:10.1016/j.carbpol.2010.07.034, 2011.

Glaser, B. and Gross, S.: Compound-specific delta C-13 analysis of individual amino sugars-a tool to quantify timing and amount of soil microbial residue stabilization, Rapid Commun. Mass Spectrom., 19, 1409-1416, doi:10.1002/rcm.1913, 2005.

Gleixner, G., Poirier, N., Bol, R., and Balesdent, J.: Molecular dynamics of organic matter in a cultivated soil, Org. Geochem., 33, 357-366, 2002.

Guenet, B., Juarez, S., Bardoux, G., Pouteau, V., Cheviron, N., Marrauld, C., Abbadie, L., and Chenu, C.: Metabolic capacities of microorganisms from a long-term bare fallow, Appl. Soil Ecol., 51, 87-93, doi:10.1016/j.apsoil.2011.07.006, 2011.

Guggenberger, G. and Zech, W.: Composition and dynamics of dissolved carbohydrates and lignin-degradation products in two coniferous forests, N.E. Bavaria, Germany, Soil Biol. Biochem., 26, 19-27, doi:10.1016/0038-0717(94)90191-0, 1994.

Guggenberger, G., Christensen, B. T., and Zech, W.: Land-use effects on the composition of organic matter in particle-size separates of soil: I. Lignin and carbohydrate signature, Eur. J. Soil Sci., 45, 449-458, doi:10.1111/j.1365-2389.1994.tb00530.x, 1994.

Gunina, A. and Kuzyakov, Y.: Sugars in soil and sweets for microorganisms: Review of origin, content, composition and fate, Soil Biol. Biochem., 90, 87-100, doi:10.1016/j.soilbio.2015.07.021, 2015.

Gunina, A., Dippold, M. A., Glaser, B., and Kuzyakov, Y.: Fate of low molecular weight organic substances in an arable soil: From microbial uptake to utilisation and stabilisation, Soil Biol. Biochem., 77, 304-313, doi:10.1016/j.soilbio.2014.06.029, 2014.

Helfrich, M., Ludwig, B., Buurman, P., and Flessa, H.: Effect of land use on the composition of soil organic matter in density and aggregate fractions as revealed by solid-state C-13 NMR spectroscopy, Geoderma, 136, 331-341, 2006.

IUSS Working Group WRB: World reference base for soil resources 2014: International soil classification system for naming soils and creating legends for soil maps, World soil resources reports, FAO, Rome, Online-Ressource, 91 pp., 2014.

Joergensen, R. G.: The fumigation-extraction method to estimate soil microbial biomass: Calibration of the kEC value, Soil Biol. Biochem., 28, 25-31, doi:10.1016/0038-0717(95)00102-6, 1996.

Joergensen, R. G. and Raubuch, M.: Adenylate energy charge and ATP-to-microbial biomass $\mathrm{C}$ ratio in soils differing in the intensity of disturbance, Soil Biol. Biochem., 35, 1161-1164, doi:10.1016/S0038-0717(03)00150-0, 2003.
John, B., Yamashita, T., Ludwig, B., and Flessa, H.: Storage of organic carbon in aggregate and density fractions of silty soils under different types of land use, Geoderma, 128, 63-79, doi:10.1016/j.geoderma.2004.12.013, 2005.

Kiem, R. and Kögel-Knabner, I.: Contribution of lignin and polysaccharides to the refractory carbon pool in C-depleted arable soils, Soil Biol. Biochem., 35, 101-118, 2003.

Kindler, R., Miltner, A., Richnow, H.-H., and Kästner, M.: Fate of gram-negative bacterial biomass in soil mineralisation and contribution to SOM, Soil Biol. Biochem., 38, 2860-2870, doi:10.1016/j.soilbio.2006.04.047, 2006.

Kögel-Knabner, I.: The macromolecular organic composition of plant and microbial residues as inputs to soil organic matter, Soil Biol. Biochem., 34, 139-162, doi:10.1016/S00380717(01)00158-4, 2002.

Kögel-Knabner, I., Zech, W., and Hatcher, P. G.: Chemical composition of the organic matter in forest soils: The humus layer, Z. Pflanz. Bodenkunde, 151, 331-340, doi:10.1002/jpln.19881510512, 1988.

Kramer, C. and Gleixner, G.: Variable use of plant- and soilderived carbon by microorganisms in agricultural soils, Soil Biol. Biochem., 38, 3267-3278, doi:10.1016/j.soilbio.2006.04.006, 2006.

Kramer, C. and Gleixner, G.: Soil organic matter in soil depth profiles: Distinct carbon preferences of microbial groups during carbon transformation, Soil Biol. Biochem., 40, 425-433, doi:10.1016/j.soilbio.2007.09.016, 2008.

Lamparter, A., Bachmann, J., M.-O. Goebel, and Woche, S.: Carbon mineralization in soil: Impact of wetting-drying, aggregation and water repellency, Geoderma, 150, 324-333, doi:10.1016/j.geoderma.2009.02.014, 2009.

Lengeler, J. W., Drews, G., and Schlegel, H. G.: Biology of the prokaryotes, Thieme, Stuttgart, 955 pp., 1999.

Lowe, L. and Brown, S.: Carbohydrates in soil, in: Soil organic matter, edited by: Schnitzer, M. and Khan, S. U., 8, Elsevier, 65-91, 1975.

Madigan, M. T., Martinko, J. M., Parker, J., Brock, T. D., and Goebel, W. (Eds.): Mikrobiologie, 2., korrigierter Nachdr, Spektrum-Lehrbuch, Spektrum Akad. Verl, Heidelberg, 1175 pp., 2003.

Malik, A., Blagodatskaya, E., and Gleixner, G.: Soil microbial carbon turnover decreases with increasing molecular size, Soil Biol. Biochem., 62, 115-118, doi:10.1016/j.soilbio.2013.02.022, 2013.

Mau, R. L., Liu, C. M., Aziz, M., Schwartz, E., Dijkstra, P., Marks, J. C., Price, L. B., Keim, P., and Hungate, B. A.: Linking soil bacterial biodiversity and soil carbon stability, ISME J., 9, $1477-$ 1480, doi:10.1038/ismej.2014.205, 2015.

Miltner, A., Kindler, R., Knicker, H., Richnow, H.-H., and Kästner, M.: Fate of microbial biomass-derived amino acids in soil and their contribution to soil organic matter, Org. Geochem., 40, 978 985, doi:10.1016/j.orggeochem.2009.06.008, 2009.

Miltner, A., Bombach, P., Schmidt-Brücken, B., and Kästner, M.: SOM genesis: microbial biomass as a significant source, Biogeochemistry, 111, 41-55, doi:10.1007/s10533-011-9658-z, 2012.

Moers, M. E. C., Baas, M., Deleeuw, J. W., Boon, J. J., and Schenck, P. A.: Occurrence and origin of carbohydrates in peat samples from a red mangrove environment as reflected by abundances of 
neutral monosaccharides, Geochim. Cosmochim. Ac., 54, 24632472, 1990.

Muramaya, S.: Decomposition kinetics of straw saccharides and synthesis of microbial saccharides under field conditions, J. Soil Sci., 35, 231-242, doi:10.1111/j.1365-2389.1984.tb00279.x, 1984.

Muramaya, S.: Microbial synthesis of saccharides in soils incubated with 13C-labelled glucose, Soil Biol. Biochem., 20, 193-199, doi:10.1016/0038-0717(88)90036-3, 1988.

Neu, T. R. and Lawrence, J. R.: Development and structure of microbial biofilms in river water studied by confocal laser scanning microscopy, FEMS Micorbiol. Ecol., 24, 11-25, doi:10.1111/j.1574-6941.1997.tb00419.x, 1997.

Nierop, K. G., van Lagen, B., and Buurman, P.: Composition of plant tissues and soil organic matter in the first stages of a vegetation succession, Geoderma, 100, 1-24, doi:10.1016/S00167061(00)00078-1, 2001.

R Core Team: R: A Language and Environment for Statistical Computing, R Foundation for Statistical Computing, Vienna, Austria, available at: http://www.R-project.org, 2013.

Rumpel, C. and Dignac, M.-F.: Gas chromatographic analysis of monosaccharides in a forest soil profile: Analysis by gas chromatography after trifluoroacetic acid hydrolysis and reduction-acetylation, Soil Biol. Biochem., 38, 1478-1481, doi:10.1016/j.soilbio.2005.09.017, 2006.

Saggar, S., Parshotam, A., Hedley, C., and Salt, G.: 14C-labelled glucose turnover in New Zealand soils, Soil Biol. Biochem., 31, 2025-2037, doi:10.1016/S0038-0717(99)00126-1, 1999.

Salomé, C., Nunan, N., Pouteau, V., Lerch, T. Z., and Chenu, C.: Carbon dynamics in topsoil and in subsoil may be controlled by different regulatory mechanisms, Glob. Change Biol., 16, 416426, doi:10.1111/j.1365-2486.2009.01884.x, 2010.

Sauheitl, L., Glaser, B., and Bol, R.: Short-term dynamics of slurryderived plant and microbial sugars in a temperate grassland soil as assessed by compound-specific delta C-13 analyses, Rapid Commun. Mass Spectrom., 19, 1437-1446, 2005.
Schmidt, M. W., Torn, M. S., Abiven, S., Dittmar, T., Guggenberger, G., Janssens, I. A., Kleber, M., Kögel-Knabner, I., Lehmann, J., Manning, D. A. C., Nannipieri, P., Rasse, D. P., Weiner, S., and Trumbore, S. E.: Persistence of soil organic matter as an ecosystem property, Nature, 478, 49-56, doi:10.1038/nature10386, 2011.

Schneckenberger, K., Demin, D., Stahr, K., and Kuzyakov, Y.: Microbial utilization and mineralization of $\left[{ }^{14} \mathrm{C}\right]$ glucose added in six orders of concentration to soil, Soil Biol. Biochem., 40, 19811988, doi:10.1016/j.soilbio.2008.02.020, 2008.

Six, J., Conant, R. T., Paul, E. A., and Paustian, K.: Stabilization mechanisms of soil organic matter: Implications for C-saturation of soils, Plant Soil, 241, 155-176, doi:10.1023/A:1016125726789, 2002.

Sollins, P., Homann P., and Caldwell BA.: Stabilization and destabilization of soil organic matter: mechanisms and controls, Geoderma, 74, 65-105, doi:10.1016/S0016-7061(96)00036-5, 1996.

Stevenson, F. J.: Humus chemistry: Genesis, composition, reactions, 2nd ed., Wiley, New York, xiii, 496 pp., 1994.

Vance, E., Brookes, P., and Jenkinson, D. S.: An extraction method for measuring soil microbial biomass C, Soil Biol. Biochem., 19, 703-707, doi:10.1016/0038-0717(87)90052-6, 1987.

von Lützow, M. von, Kögel-Knabner, I., Ekschmitt, K., Matzner, E., Guggenberger, G., Marschner, B., and Flessa, H.: Stabilization of organic matter in temperate soils: mechanisms and their relevance under different soil conditions - a review, Eur. J. Soil Sci., 57, 426-445, doi:10.1111/j.1365-2389.2006.00809.x, 2006.

Waldrop, M. and Firestone, M.: Microbial community utilization of recalcitrant and simple carbon compounds: impact of oak-woodland plant communities, Oecologia, 138, 275-284, doi:10.1007/s00442-003-1419-9, 2004.

Wilson, W. A., Roach, P. J., Montero, M., Baroja-Fernández, E., Muñoz, F. J., Eydallin, G., Viale, A. M., and Pozueta-Romero, J.: Regulation of glycogen metabolism in yeast and bacteria, FEMS Microbiol. Rev., 34, 952-985, doi:10.1111/j.15746976.2010.00220.x, 2010. 